\title{
NEONATAL-SEPSIS CAUSATIVE MICROORGANISMS AND ANTIMICROBIAL SENSITIVITY IN NICU, CHILDREN HOSPITAL AND INSTITUTE OF CHILD HEALTH, MULTAN.
}

\author{
1. MBBS, DCH, FCPS (Pediatrics) \\ FCPS (Neonatology) \\ Assistant Professor \\ Department of Neonatology \\ Children Hospital and \\ Institute of Child Health, Multan. \\ 2. MBBS, FCPS (Pediatrics) \\ Assistant Professor \\ Bakhtawar Ameen Medical and \\ Dental College Multan. \\ 3. FCPS (Pediatrics) \\ FCPS (Neonatology) \\ Senior Registrar \\ Children Hospital and \\ Institute of Child Health, Multan. \\ 4. MBBS, FCPS (Pediatrics) \\ Head \\ Department of Paediatrics \\ Children Hospital and \\ Institute of Child Health, Multan. \\ 5. MBBS, MCPS \\ Admin Registrar \\ Department of Neonatology \\ Children Hospital and \\ Institute of Child Health, Multan. \\ 6. MBBS \\ Medical Officer \\ Children Hospital and \\ Institute of Child Health, Multan.
}

Correspondence Address:

Dr. Abdur Rehman

Rahim Colony, Street No.3,

Near Art Council Park Multan.

dr. armalik@outlook.com

Article received on:

18/09/2018

Accepted for publication:

08/02/2019

Received after proof reading:

28/08/2019

\begin{abstract}
Abdur Rehman ${ }^{1}$, Ahmed Iqbal Quddusi ${ }^{2}$, Nazia Fatima ${ }^{3}$, Imran Iqbal ${ }^{4}$, Ashee Nadeem ${ }^{5}$, Sidra Khan ${ }^{6}$
ABSTART... Objectives: The objective of this study was to identify the microorganisms and antimicrobial susceptibility pattern of neonatal septicemia in NICU, Children Hospital and Institute of Child Health, Multan. Study Design: Descriptive study. Setting: Neonatal Intensive Care Unit of NICU, Children Hospital and Institute of Child Health, Multan. Period: 6 months from October 2017-March 2018. Material and Methods: In this study a total of 173 specimen were cultured including peripheral samples 160 (92.5\%), tips of endotracheal tubes $8(4.6 \%)$ and tracheal aspirates $5(2.8 \%)$. Our patients were newborns age ranging from $5-19$ days who were admitted due to suspected septicemia. Specimens were sent to Shaukat Khanam Memorial Hospital Lahore and Aga Khan University Hospital, Karachi where they were cultured by using standard microbiological methods. The necessary information's regarding age of the neonates, weight, gestational age, mode of delivery, prior use of antibiotics and outcome were recorded on predesigned data collection sheet. Results were analyzed by using statistical tools. Results: The outcome of 173 specimens, microbial testing showed that $91(53 \%)$ isolates were found to be positive. Out of these $91,77(85 \%)$ were Bacterial and $14(15 \%)$ were fungal species. The incidence of Gram Negative and Gram Positive bacteria was found to be $62(68 \%)$ and $15(16 \%)$ respectively. The most common gram negative specie was Klebsiella Pneumonia 20 (32\%). Among gram positive bacteria staphylococcus epidermidis $15(67 \%)$ was the most common species. Among fungal species Candida sepsis was the most common, $13(14 \%)$ of all the samples. Most of the gram negative organisms were sensitive to Aminoglycosides, Imipenem and Ciprofloxacin. Gram positive species were sensitive to Linezolid and Vancomycin. All the fungal species were sensitive to Fluconazole and Voriconazole. Conclusion: There is a variety of organisms causing neonatal septicemia in Tertiary Care hospitals with variable susceptibility pattern, which reflects the need to evaluate the incidence of different microbial species after every quarter and study there susceptibility patterns.
\end{abstract}

Key words: $\quad$ Antibiotic, Blood Culture, Micro Organism, Neonate, Sepsis.

Article Citation: Rehman A, Quddusi Al, Fatima N, Iqbal I, Nadeem A, Khan S. Neonatalsepsis causative microorganisms and antimicrobial sensitivity in NICU, Children Hospital and Institute of Child Health, Multan. Professional Med J 2019; 26(9):1570-1575. DOI: 10.29309/TPMJ/2019.26.09.4028

\section{INTRODUCTION}

Infections are frequent and important cause of morbidity and mortality in neonatal period. ${ }^{1}$ Neonatal infection can be divided by age of onset of symptoms (early- onset if in the first 72 hour of life, late-onset if after 72 hours of life). Intrapartum infections cause mainly early onset sepsis and late onset infections may community or hospital acquired. ${ }^{2}$ Neonates may be infected at different times via three different routes: in utero (transplacental), intrapartum (ascending), and post-partum (nosocomial or community). The timing of exposure, inoculum size, immune status and virulence of infectious agents influence the manifestations of disease. ${ }^{3}$

Several factors influence the incidence of neonatal infection, such as the mode of delivery, gestational age, birth weight, maternal age, maternal immunization status, and the presence of maternal infections such as chrioamniotis. Moreover environmental factors can influence the incidence of infection. e.g. the prevalence of organism in community, the place of birth and neonatal stay ( home or hospital), socio-economic status and ethnicity. ${ }^{4}$ Invasive procedures, the 
presence of indwelling catheters, ventricular shunts, endotracheal tubes, and alterations in the skin and mucus membrane barriers may favor infections. Previous used of antibiotics increases the likelihood of infections caused by more resistant bacteria and fungi. ${ }^{4,5}$

\section{CRITERIA FOR THE DIAGNOSIS OF SEPSIS ${ }^{6}$}

(High sensitivity CRP, serum soluble intercellular adhesion molecule 1 , soluble e- selectin and serum amyloid a individually or in combination will be the future specific markers for sepsis)

\section{Proven Sepsis}

A positive blood culture or PCR in the presence of clinical signs and symptoms of infection. For CoNS two positive blood cultures or one positive blood culture plus a positive CRP.

\section{Probable Sepsis}

Presence of signs and symptoms of infection and at least two abnormal laboratory results when blood culture is negative.

\section{Possible Sepsis}

Presence of clinical signs and symptoms of infection plus raised CRP or IL-6/IL-8 level when blood culture is negative.

In industrialized countries, the incidence of neonatal bacterial sepsis is between 1 and $4 / 1000$ live births and that of meningitis between 0.2 and $0.4 / 1000$ live births. In premature infants, especially admitted to NICU, these values can be 10- fold higher. ${ }^{7}$ These incidence are significantly increased in resource poor countries. With advances in neonatal intensive care, increasingly immature, very low birth weight newborns are surviving, remaining in hospital for long periods of time where they were at risk for hospital acquired infection. ${ }^{4-6}$

A wide variety of pathogens can affect the new born, including bacteria, viruses, fungi and protozoa. Common Pathogens of neonatal sepsis in developed countries are (Early onset sepsis- Group B Streptococcus, E. coli, S. aureus, CONS, L. monocytogenes. Late onset sepsis- Coagulase-negative Staphylococcus, E. coli, Klebsiella sp., S. aureus, Candida albicans \& P. aureginosa). Common pathogens of neonatal sepsis in developing countries are (Early onset sepsis- Klebsiella, S. aureus, E. coli, Group B Streptococcus, S. pneumonia, Salmonella sp. Late onset sepsis- Klebsiella sp., S. aureus, E. coli, Coagulase-negative Staphylococcus, Pseudomonas, Enterobacter \& Candida. ${ }^{8}$

The purpose of study was to know the bacteriologic profile and recognition of the role and importance of antimicrobial stewardship in preventing infections and minimizing antimicrobial resistance.

\section{MATERIAL AND METHOD}

This was a descriptive study conducted over a period of 6 months from October 2017-March 2018, at NICU, Children Hospital and Institute of Child Health, Multan.

\begin{tabular}{|c|c|c|}
\hline Clinical Variables & $\begin{array}{l}\text { Hemodynamic Variables/ Tissue } \\
\text { Perfusion Variables }\end{array}$ & Inflammatory Variables \\
\hline Temperature instability & $\begin{array}{l}\text { Blood pressure } 2 \text { SD below normal } \\
\text { for age }\end{array}$ & $\begin{array}{l}\text { WBC count }>30,000 \_109 / 1 \\
\text { OR }<5000 \_109 / 1\end{array}$ \\
\hline $\begin{array}{l}\text { Heart rate }>180 \text { beats } / \mathrm{min} \text { or }<100 \\
\text { beats } / \mathrm{min}\end{array}$ & $\begin{array}{l}\text { Systolic pressure } \quad<50 \mathrm{~mm} \quad \mathrm{Hg} \\
\text { (newborn day 1) }\end{array}$ & Immature neutrophil >10\% \\
\hline $\begin{array}{l}\text { Respiratory rate }>60 \text { breaths/min } \\
\text { plus grunting or de saturations }\end{array}$ & $\begin{array}{l}\text { Systolic pressure }<65 \mathrm{~mm} \mathrm{Hg} \text { (infants } \\
\text { _ } 1 \text { month) }\end{array}$ & Immature: Total neutrophil ratio $>0.2$ \\
\hline Lethargy/altered mental status & Capillary refill >3 s & $\mathrm{CRP}>10 \mathrm{mg} / \mathrm{l}$ \\
\hline $\begin{array}{l}\text { Glucose intolerance (plasma glucose } \\
>10 \mathrm{mmol} / \mathrm{l} \text { ) }\end{array}$ & Plasma lactate $>3 \mathrm{mmol} / \mathrm{l}$ & Pro-calcitonin $>8.1 \mathrm{mg} / \mathrm{dl}$ \\
\hline Feed intolerance & & IL-6 or IL-8 $>70 \mathrm{pg} / \mathrm{ml}$ \\
\hline
\end{tabular}


Informed and written consents were obtained from the parents and benefits of study were explained them. A detailed history, such as neonatal age, sex, the mode of delivery, the place of birth and neonatal stay (home or hospital), gestational age (confirmed from the mother by the last date of menstrual period), birth weight, maternal age, prior use of antibiotics, maternal immunization status, the presence of maternal infections such as chrioamniotis, history of prolong/premature rupture of membrane, socioeconomic status, any Invasive procedure done on baby before admission in our hospital, the presence of indwelling catheters, ventricular shunts and endotracheal tubes, was obtained. A detailed physical examination including gestation age (using New Ballard Score) and alterations in the skin and mucus membrane barriers (favoring infections) was done.

In this study a total of 173 isolates in the form of blood samples (160), tips of endotracheal tubes $^{8}$ and tracheal aspirates ${ }^{5}$ were collected from neonates of age ranging from 5 - 19 days who were admitted due to suspected septicemia. Isolates were sent to Shaukat Khanam Memorial Hospital Lahore and Aga Khan University Hospital, Karachi where they were analyzed by using standard microbiological methods. Outcome were recorded on predesigned data collection sheet. Results were analyzed by using statistical tools.

\section{RESULTS}

The outcome of microbial testing showed that 91 (53\%) isolates showed microbial growth. Out of these 91, 77 (85\%) were Bacterial and 14 (15\%) were fungal species. The incidence of Gram Negative and Gram Positive bacteria was found to be 62 (68\%) and 15 (16\%) respectively. (Figure-1)

The most common gram negative specie was Klebsiella Pneumonia 20 (32\%) followed by Escherichia Coli 12 (19\%) and Acinobacter 8 (13\%), among the Enterobacteriaceae class of Gram negative bacteria after Klebsiella Pneumonia, Citrobacter 6 (10\%) was the common species. (Figure-2)
Among gram positive bacteria staphylococcus epidermidis 10 (67\%) was the most common species followed by Staphylococcus aureus 5 (33\%). No other species of Gram Positive bacteria was reported. (Figure-3)

Among fungal species Candida sepsis was the most common and accounted for $13(93 \%)$ of all the samples, only one isolate was found to be positive for Rhodotorula strains. (Figure-4)

Most of the gramnegativeorganismsweresensitive to Aminoglycosides, Imipenem and Ciprofloxacin, few species were also sensitive to colistin/ polmyxin-b. (Table-I) Gram positive species were sensitive to Linezolid and Vancomycin whereas third generation cephalosporin's were found to be more sensitive in Gram Negative species as compared to gram positive. (Table-II) All the fungal species were sensitive to Fluconazole and Voriconazole.

\section{Distribution Frequency of Neonatal Septicemia}

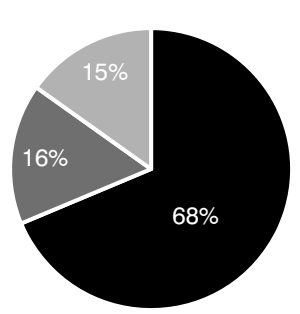

- Gram -Ve Gram +Ve Fungal

Figure-1

Distribution Frequency of Gram Negative Bacteria
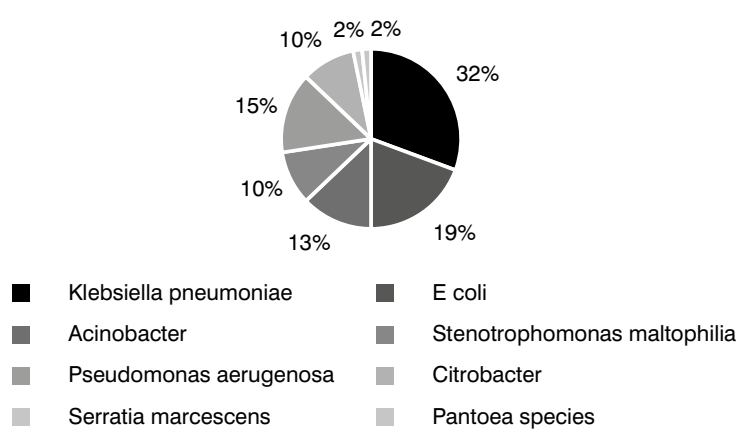

Figure-2 
Distribution Frequency of Gram Positive Bacteria

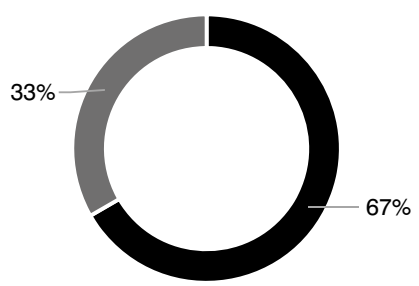

- Staph epidermidis

- staphylococcus aureus

Figure-3

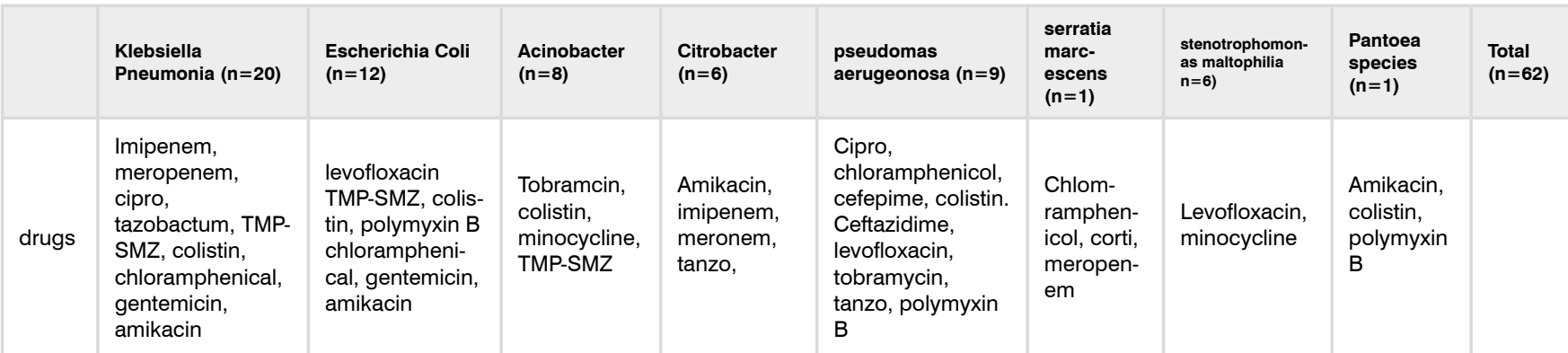

Table-I. Antibiotic sensitivity pattern of gram negative isolates

\begin{tabular}{|l|c|c|c|}
\hline \multicolumn{1}{|c|}{ Drug } & $\begin{array}{c}\text { staphylococcus } \\
\text { epidermidis (n=10) }\end{array}$ & Staphylococcus aureus $(\mathbf{n = 5 )}$ & Total (n=15) \\
\hline Linezolid & $10(100 \%)$ & $4(80 \%)$ & $14(93 \%)$ \\
\hline Vancomycin & $10(100 \%)$ & $5(100 \%)$ & $15(100 \%)$ \\
\hline Amikacin & $5(50 \%)$ & $0(0 \%)$ & $5(33 \%)$ \\
\hline Amoxicillin-clavinate & $2(25 \%)$ & $2(50 \%)$ & $4(27 \%)$ \\
\hline Azithromycin & $0(0 \%)$ & $0(0 \%)$ & $0(0 \%)$ \\
\hline Cefoperazone+ Salbactum & $0(0 \%)$ & $0(0 \%)$ & $0(0 \%)$ \\
\hline Ceftazidime & $0(0 \%)$ & $0(0 \%)$ & $0(0 \%)$ \\
\hline
\end{tabular}

Table-II. Antibiotic sensitivity pattern of gram positive isolates

\section{DISCUSSION}

For appropriate and empirical treatment, information of bacteriological profile and pattern of sensitivity is most important. Profiles of bacteria and their sensitivity differs in different parts of the world. In the current study, $53 \%$ isolates were found to be positive for blood culture positivity. In an Indian study, Sharma $\mathrm{RS}$ et $\mathrm{al}^{9}$ found that $43.6 \%$ blood culture were positive while others found similar data as well. ${ }^{10-12}$

In the present study, the incidence of Gram Negative and Gram Positive bacteria were found to be 62 (68\%) and 15 (16\%) respectively. Gram negative organisms constituted a major portion in earlier findings ${ }^{9}$ which also correlates with current findings and those of Kamble et $\mathrm{al}^{13}$ and Jain et al. ${ }^{11}$ Among gram negative organisms most frequently isolated organism was Klebsiella species. Similar results were also found by Jyothi et al. ${ }^{14}$ In the current study, it was found that most common gram negative specie was Klebsiella Pneumonia (32\%) followed by Escherichia Coli (19\%) and Acinobacter (13\%), among the Enterobacteriaceae class of Gram negative bacteria after Klebsiella Pneumonia, Citrobacter $(10 \%)$ was the most common species. Sharma et $\mathrm{al}^{9}$ also found that among gram negative isolates 
prevalence of Citrobacter species was $16.32 \%$ but compared to other studies done previously by Nayar et $\mathrm{al}^{15}(2.1 \%)$, Bhat et $\mathrm{al}^{16}(3.05 \%)$, this was quite a high number.

Among gram positive bacteria staphylococcus epidermidis (66\%) was the most common species followed by Staphylococcus aureus (34\%). Similar results have been found by earlier findings $s^{9,10}$ that shown that geographical patterns are quite similar in this part of the world.

In this study, most of the gram negative organisms were sensitive to Aminoglycosides, Imipenem and Ciprofloxacin, few species were also sensitive to colistin/polmyxin-b. Gram positive species were sensitive to Linezolid and Vancomycin, third generation cephalosporin's were found to be more sensitive in Gram Negative species as compared to gram positive. All the fungal species were sensitive to Fluconazole and Voriconazole. Gram negative organisms (Klebsiella species, Citrobacter species), Streptococcus, Staphylococcus are known to be the leading cause of neonatal sepsis around the world. ${ }^{9}$ Because mortality from untreated sepsis can be as high as 50\%, ${ }^{17}$ most clinicians believe that the hazard of untreated sepsis is too great to allow them to wait for confirmation in the form of positive culture results. Therefore, most clinicians initiate treatment while awaiting culture results. There are high levels of resistance to routinely used antibiotics among them. We should revise our antibiotic treatment policy and emphasize on rationale antibiotic use. Second and third line antimicrobial should not be used as empirical treatment especially in low income countries like Pakistan where culture and sensitivity facilities not easily available.

\section{CONCLUSION}

There is an increasing incidence of neonatal septicemia in Tertiary Care settings, which reflects the need to evaluate the incidence of different microbial species after every quarter and study there susceptibility patterns. This will help the community to develop strategies for its effective control, monitoring and choice of antibiotics.

Copyright@ 08 Feb, 2019.

\section{REFERENCES}

1. Mukhopadhyay S, Puopolo KM. Risk assessment in neonatal early onset sepsis. Semin Perinatol 2012; 36:408-15.

2. Simonsen KA, Anderson-Berry AL, Delair SF, Davies HD. Early-onset neonatal sepsis. Clin Microbiol Rev 2014; $27: 21-47$.

3. Ohlin A, Bjorkqvist M, Montgomery SM, Schollin J. Clinical signs and CRP values associated with blood culture results in neonates evaluated for suspected sepsis. Acta Paediatr 2010; 99:1635-40.

4. Dessi A, Corsello G, Stronati M et al, New diagnostic possibilities in systemic neonatal infections: metabolomics. Early Hum Dev2014; 90 (Suppl 1): S19-21.

5. Izquierdo-Garcia JL, Nin N, Ruiz-Cabello $J$ et al, A metabolomic approach for diagnosis of experimental sepsis. Intensive Care Med2011; 37:2023-32.

6. Wynn JL. Defining neoanatal sepsis. Current opinion in pediatrics. $2016 ; 28(2): 135-140$.

7. Kliegman RM, Stanton B, Geme JW, Schor NF, Richard $E$. Infections of the infants. In: Nelson textbook of pediatrics (edition 20). Elsevier.

8. Simonsen KA, Anderson-Berry AL, Delair SF, Davies HD. Early-onset neonatal sepsis. Clinical Microbiology Reviews. 2014; 27(1):21-47.

9. Sharma RS, Tiwari M, Bansal RP. Neonatal septicemia: Isolates and their sensitivity pattern with emergence of Citrobacter septicemia. Int J Res Med Sci. 2016 Apr; 4(4):1128-31.

10. Desai KJ, Malek SS. Neonatal septicemia: Bacterial isolates \& their antibiotics susceptibility patterns. NJIRM. 2010; 1 (3):13-5.

11. Jain A, Roy I, Gupta MK, Kumar M, Agarwal SK. Prevalence of extended-spectrum beta lactamase producing Gram-negative bacteria in septicaemic neonates in a tertiary care hospital. Journal of Medical Microbiology. 2003; 52:421-5.

12. Chandel DS, Johnson JA, Chaudhry R, Sharma $\mathrm{N}$, Shinkre N, Parida S, et al. Extended-spectrum b-lactamase-producing Gram-negative bacteria causing neonatal sepsis in India in rural and urban settings. Journal of Medical Microbiology. 2011; 60:500-7. 
13. Kamble R, Ovhal R. Bacteriological profile of neonatal septicaemia. Int J Curr Microbiol App Sci. 2015; 4(2):172-82.

14. Jyothi P, Basavaraj MC, Basavaraj PV. Bacteriological profile of neonatal septicemia and antibiotic susceptibility pattern of the isolates. J Nat Sci Biol Med. 2013; 4(2):306-9.
15. Nayar N, Shukla I, Sultan A. Epidemiology, prevalence and identification of citrobacter species in clinical specimens in a Tertiary Care Hospital in India. International Journal of Scientific and Research Publications. 2014; 4(4):1-6.

\section{AUTHORSHIP AND CONTRIBUTION DECLARATION}

\begin{tabular}{|c|c|c|c|}
\hline Sr. \# & Author-s Full Name & Contribution to the paper & Author $=\mathbf{s}$ Signature \\
\hline 1 & Abdur Rehman & $\begin{array}{l}\text { Abstract, Introduction, } \\
\text { Discussion, Research. }\end{array}$ & Acallin \\
\hline 2 & Ahmed lqbal Quddusi & Discussion. & \\
\hline 3 & Nazia Fatima & Data collection & \\
\hline 4 & Imran Iqbal & $\begin{array}{l}\text { Abstract, Introduction, } \\
\text { discussion, Resutls. }\end{array}$ & \\
\hline 5 & Ashee Nadeem & Data collection, result. & \\
\hline 6 & Sidra Khan & Data collection, result. & \\
\hline
\end{tabular}

